\title{
Current practice in hemodynamic monitoring and management in high-risk surgery patients: a national survey of Korean anesthesiologists
}

\author{
Sang-Hyun Kim ${ }^{1}$, Min-Jae Kim ${ }^{1}$, Joon-Ho Lee ${ }^{1}$, Sung-Hwan $\mathrm{Cho}^{1}$, Won-Seok Chae ${ }^{1}$, and \\ Maxime Cannesson ${ }^{2}$ \\ ${ }^{1}$ Department of Anesthesiology and Pain Medicine, Soonchunhyang University Bucheon Hospital, Bucheon, Korea, \\ ${ }^{2}$ Department of Anesthesiology and Perioperative Care, University of California, Irvine, USA
}

Background: Hemodynamic optimization improves postoperative outcomes in high-risk surgery patients. The monitoring of cardiac output (CO) and dynamic parameters of fluid responsiveness can guide hemodynamic optimization. We conducted a survey to assess the current hemodynamic monitoring and management practices of Korean anesthesiologists during high-risk surgery.

Methods: E-mails containing a link to our survey, which consisted of 33 questions relating to hemodynamic monitoring during high-risk surgery, were sent to 3,943 members of the Korean Society of Anesthesiologists (KSA). The survey web page was open from December 30, 2011 to March 31, 2012.

Results: A total of 139 anesthesiologists responded during the survey period. Invasive arterial pressure (97.2\%) and central venous pressure (93.4\%) were routinely monitored. CO was monitored in $58.5 \%$ of patients; stroke volume variations were monitored in $50.9 \%$ of patients. However, $\mathrm{CO}$ was consistently optimized by $<20 \%$ of anesthesiologists. An arterial pressure waveform-derived CO monitor was the most frequently used device to monitor $\mathrm{CO}$ (79.0\%). Blood pressure, urine output, central venous pressure, and clinical experience were considered to be the best indicators of volume expansion than $\mathrm{CO}$ or dynamic parameters of fluid responsiveness.

Conclusions: The survey revealed that KSA members frequently monitor CO and dynamic parameters of fluid responsiveness during high-risk surgery. However, static indices were used more often to judge volume expansion. The current study reveals that $\mathrm{CO}$ is not frequently optimized despite the relatively high incidence of $\mathrm{CO}$ monitoring during high-risk surgery in Korea. (Korean J Anesthesiol 2013; 65: 19-32)

Key Words: Cardiac output, Hemodynamics, Intraoperative, Monitoring, Treatment outcome.

\footnotetext{
Received: November 8, 2012. Revised: 1st, December 22, 2012; 2nd, February 11, 2013. Accepted: February 21, 2013.

Corresponding author: Sang-Hyun Kim, M.D., Ph.D., Department of Anesthesiology and Pain Medicine, Soonchunhyang University Bucheon Hospital, 1174, Jung-dong, Wonmi-gu, Bucheon 420-767, Korea. Tel: 82-32-621-5328, Fax: 82-32-621-5328, E-mail: skim@schmc.ac.kr (c) This is an open-access article distributed under the terms of the Creative Commons Attribution Non-Commercial License (http:// creativecommons.org/licenses/by-nc/3.0/), which permits unrestricted non-commercial use, distribution, and reproduction in any medium, provided the original work is properly cited.
} 


\section{Introduction}

Hemodynamic management in high-risk surgery patients is a challenge for anesthesiologists. Clinical variables such as arterial blood pressure (BP), heart rate (HR), and urine output (UO) do not detect tissue hypoperfusion during the early stage of surgery. Furthermore, static parameters such as central venous pressure (CVP) and pulmonary capillary wedge pressure (PCWP) reportedly provide little information regarding preload or fluid responsiveness [1,2]. Fluid management focusing on these parameters may under- or over-hydrate patients, which can increase postoperative morbidity [3]. Initially, the goal of hemodynamic intervention was to maintain supra-normal oxygen delivery $\left(\mathrm{DO}_{2}\right)$ by maintaining a certain level of flowrelated hemodynamic variables, including cardiac output (CO) by administering fluid, drugs, or blood products. Following a historical report showing that an increase in CO measured using a pulmonary artery catheter (PAC) improved postoperative outcomes [4], several studies have demonstrated the benefits of a hemodynamic optimization protocol [5-7].

Previously, the hemodynamic management of $\mathrm{CO}$ or $\mathrm{DO}_{2}$ required invasive techniques such as a $\mathrm{PAC}$; however, technological advances have made minimally or noninvasive $\mathrm{CO}$ monitoring techniques readily available [8-10] for clinicians to use goal-directed hemodynamic management in high-risk surgery patients. The findings of recent meta-analyses confirmed that preemptive hemodynamic intervention or the maintenance of tissue perfusion decreased postoperative mortality, morbidity, and organ failure $[11,12]$. Furthermore, dynamic parameters of fluid responsiveness such as stroke volume variation (SVV), pulse pressure variation (PPV), and the pleth variability index (PVI) can reveal variations in stroke volume induced by cardiopulmonary interactions during mechanical ventilation and identify patients who need fluid administration to increase their CO [13-15]. Thus, minimally invasive CO monitors and surrogates for predicting fluid responsiveness are available for anesthesiologists as routine hemodynamic monitors to optimize the hemodynamic status of high-risk surgery patients. However, a previous survey of American and European anesthesiologists showed that a considerable gap exists between the perceived benefits of hemodynamic optimization and clinical implementation of the available technology [16].

The present survey aimed to assess current hemodynamic monitoring and management of high-risk surgery patients among South Korean anesthesiologists.

\section{Materials and Methods}

Our Institutional Review Board approved the survey. The target population was board-certified members of the Korean
Society of Anesthesiologists (KSA). The KSA office e-mail database includes the e-mail addresses of 3,943 board-certified anesthesiologists registered with the organization, but about 1,000 addresses are invalid. After excluding invalid addresses, the remainder includes members who no longer practice anesthesia (e.g., pain clinicians, honorary members, and retired members). All e-mails were sent by the KSA and no e-mail addresses were provided to the authors. Two methods were used to distribute the survey to maximize the response rate and participation. The initial invitation to participate appeared in the KSA e-newsletter. One week later, an e-mail inviting participation was sent to each of the 3,943 members of the KSA. Finally, a follow-up e-mail was sent to respondents and nonrespondents 6 weeks after the first e-mail; thus, a total of three e-mail invitations to join the study were issued.

The invitation cover letter included the purpose of the survey, the name and affiliation of the researcher, and the potential benefit of the survey. The cover letter encouraged respondents to participate, and a link to the survey web page was shown at the end of the letter (www.surveymonkey.com). The survey was open for 3 months, from December 30, 2011 to March 31, 2012.

\section{Survey description}

We adopted the definition of a high-risk surgery patient used in previous studies for noncardiac surgery $[16,17]$. The criteria included patients aged 18 years or older presenting for major surgery with an expected duration of more than $1.5 \mathrm{~h}$ and having at least two of the following:

1. Cardiac or respiratory illness resulting in functional limitations

2. Extensive surgery planned for carcinoma involving bowel anastomosis

3. Predictable acute massive blood loss $(>2.5 \mathrm{~L})$

4. Aged $>70$ years with a functional limitation in one or more organ systems

5. Septicemia (positive blood culture or septic focus)

6. Respiratory failure $\left(\mathrm{PaO}_{2}<60 \mathrm{mmHg}\right.$ on $\mathrm{FiO}_{2}>0.4$; that is, $\mathrm{PaO}_{2}: \mathrm{FiO}_{2}$ ratio of $<150 \mathrm{mmHg}$ or ventilation $>48 \mathrm{~h}$ )

7. Acute abdominal catastrophe (e.g., pancreatitis, perforated viscous, or gastro-intestinal bleed)

8. Acute renal failure (urea $>20 \mathrm{mmol} / \mathrm{L}$ and creatinine $>260 \mu \mathrm{mol} / \mathrm{L}$ )

9. Surgery for abdominal aortic aneurysm

10. Disseminated malignancy

The survey contained 33 questions divided into two parts consisting of respondent demographic data (14 questions) and clinical experience in the anesthetic management of high-risk surgical patients (19 questions). The questionnaire was identical to that published in 2011 with the exception that the present survey 
asked for the city in which the respondent practiced [16]. The full questionnaire used in this survey is shown in the Appendix.

\section{Questions regarding the current practice of hemodynamic monitoring in high-risk surgery patients}

\section{Routine hemodynamic monitoring and hemodynamic optimization}

Questions were asked concerning the respondent's routine hemodynamic monitoring practice and the intraoperative frequency with which they optimized parameters of hemodynamic monitoring such as invasive arterial pressure (IAP), $\mathrm{CVP}, \mathrm{CO}$, mixed venous oxygen saturation $\left(\mathrm{Svo}_{2}\right)$, central venous oxygen saturation $\left(\mathrm{Scvo}_{2}\right)$, and dynamic parameters of fluid responsiveness such as $\mathrm{PPV}$, systolic pressure variation (SPV), and plethysmographic waveform variation. The respondents were asked which methods they used to evaluate the dynamic parameters of fluid responsiveness, and at what point during surgery optimization procedures were performed.

\section{CO monitoring}

Respondents were asked what technique they currently used to monitor $\mathrm{CO}$, and if they did not routinely monitor $\mathrm{CO}$, they were asked to indicate why.

\section{Volume management}

Four questions on volume management included diagnostic indicators of volume expansion, an assessment of the hemodynamic effect of volume expansion, the best predictor of volume expansion, and the type of fluid used for volume expansion.

\section{Other questions}

We asked the respondents whether they believed oxygen delivery to tissues was of major importance and whether they felt their current hemodynamic management approach could be improved.

\section{Statistics}

Respondents who did not perform or directly supervise anesthesia for high-risk patients were excluded from the analysis. The data are expressed as the number of respondents and percentages. Results from a previously published survey conducted among American Society of Anesthesiology (ASA) and European Society of Anesthesiology (ESA) members were included for comparison [16]. All statistical tests were conducted using the Statistical Package for the Social Sciences version 14.0 (SPSS Inc., Chicago, IL, USA).

\section{Results}

We received 139 responses from KSA members. Of those, 22 indicated that they did not administer or supervise anesthesia for high-risk patients. Among the remaining 117 respondents, 6 did not answer any further questions and were excluded from the analysis. The remaining 111 respondents were included in the analysis, and, of those, 70 (63\%) completed the entire questionnaire.

\section{Demographic data}

Most of the respondents worked at university (79\%) or general (19\%) hospitals. In a typical work week, they reported administering or directly supervising anesthesia for high-risk patients 1-5 times (61\%), 6-10 times (19\%), or $>11$ times (10\%). More than half reported that they administered anesthesia for various types of surgery. We found that $13 \%$ of the respondents were cardiac anesthesiologists and $9 \%$ were transplant anesthesiologists.

Furthermore, $30 \%$ of the respondents worked at a hospital with more than 1,000 beds, $60 \%$ worked at hospitals with $500-$ 1,000 beds, $59 \%$ worked in hospitals with $>40$ intensive care unit beds, $50 \%$ of respondents finished training after the year 2000, and $60 \%$ of the respondents completed fellowship training. The most frequent fellowship was cardiac anesthesia (33\%) followed by critical care, pain, research, and transplant anesthesia. About $70 \%$ of respondents practiced in Seoul, Gyeonggi, and Busan.

\section{Questions regarding the current practice of hemodynamic monitoring in high-risk surgery patients}

Two-thirds (66\%) of 109 respondents reported that their institution or group did not have a written protocol, care guide,

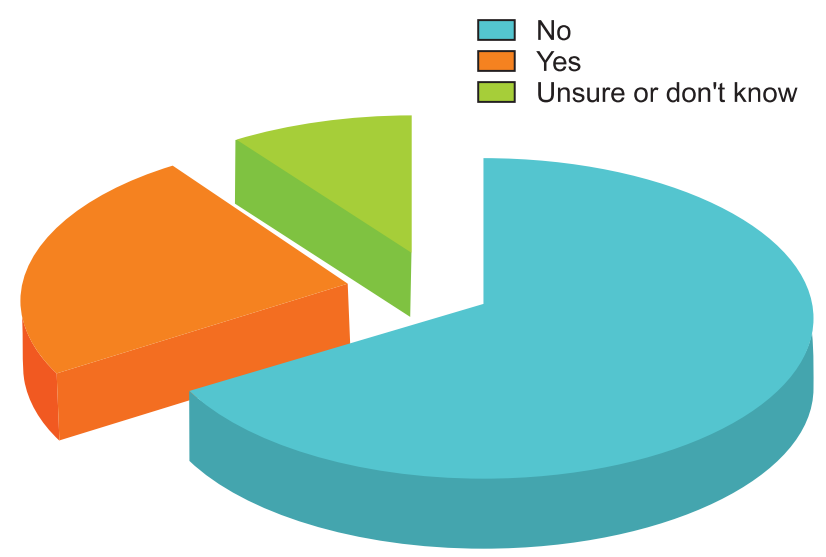

Fig. 1. Does your institution or group have a written protocol, care guide, or statement concerning hemodynamic management in this setting? 
or statement concerning hemodynamic management in highrisk surgery patients; $10 \%$ answered that they were unsure or did not know, whereas $24 \%$ reported that a protocol was in place (Fig. 1).

\section{Routine hemodynamic monitoring and hemodynamic optimization}

The most commonly reported methods for routine hemodynamic monitoring were IAP (97\%) and CVP (93\%), followed by CO (59\%) and SVV (51\%) (Table 1$)$.

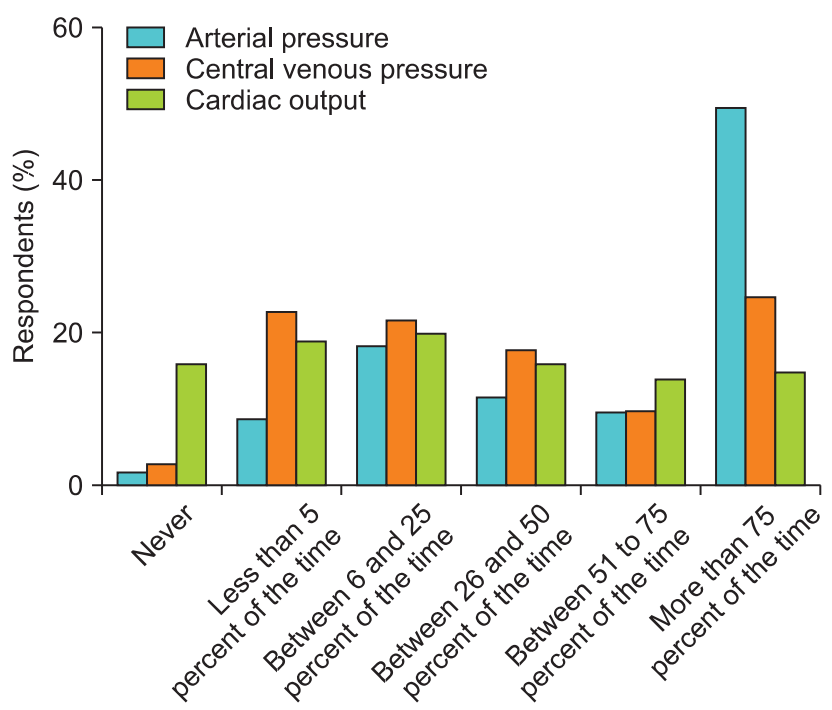

Fig. 2. How frequently do you try to optimize arterial pressure, central venous pressure, and cardiac output in this setting?
The frequency of intraoperative hemodynamic optimization for $>50 \%$ of the time for each parameter was highest for BP followed by CVP and CO (Fig. 2). In contrast, no respondent reported optimizing $\mathrm{Scvo}_{2}$ or $\mathrm{Svo}_{2}>50 \%$ of the time. Approximately $60 \%$ of the respondents reported that they optimized hemodynamics during surgery and after the induction of anesthesia. Half of the respondents regarded the intraoperative period as the most critical time for hemodynamic optimization.

\section{CO monitoring}

The most frequently used CO monitoring device was the Flotrac/Vigileo monitor (79\%) followed by the Swan Ganz catheter (52\%), transesophageal echocardiography (TEE, 32\%), and esophageal Doppler (13\%) (Fig. 3). The two main reasons

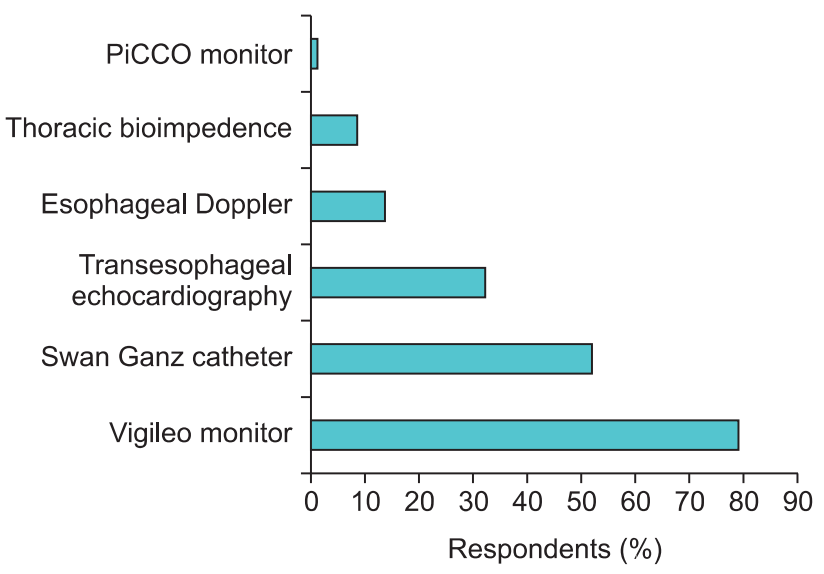

Fig. 3. What technique do you use to monitor cardiac output?

Table 1. What Hemodynamic Monitoring Do You Routinely Use for the Management of High-risk Surgery Patients? (Please, Mark All That Apply)

\begin{tabular}{|c|c|c|c|}
\hline \multirow{2}{*}{ Answer options } & KSA respondents $(\mathrm{n}=106)$ & ASA respondents $(\mathrm{n}=237)$ & ESA respondents $(n=195)$ \\
\hline & Response percent & Response percent & Response percent \\
\hline Invasive arterial pressure & $97.2 \%$ & $95.4 \%$ & $89.7 \%$ \\
\hline Central venous pressure & $93.4 \%$ & $72.6 \%$ & $83.6 \%$ \\
\hline Non-invasive arterial pressure & $64.2 \%$ & $51.9 \%$ & $53.8 \%$ \\
\hline Cardiac output & $58.5 \%$ & $35.4 \%$ & $34.9 \%$ \\
\hline Pulmonary capillary wedge pressure & $25.5 \%$ & $30.8 \%$ & $14.4 \%$ \\
\hline Transesophageal echocardiography & $31.1 \%$ & $28.3 \%$ & $19.0 \%$ \\
\hline Systolic Pressure Variation & $28.3 \%$ & $20.3 \%$ & $23.6 \%$ \\
\hline Plethysmographic Waveform Variation & $19.8 \%$ & $17.3 \%$ & $17.9 \%$ \\
\hline Pulse Pressure Variation & $29.2 \%$ & $15.2 \%$ & $25.6 \%$ \\
\hline Mixed venous saturation $\left(\mathrm{SvO}_{2}\right)$ & $18.9 \%$ & $14.3 \%$ & $15.9 \%$ \\
\hline Central venous saturation $\left(\mathrm{ScvO}_{2}\right)$ & $24.5 \%$ & $12.7 \%$ & $33.3 \%$ \\
\hline Oxygen delivery $\left(\mathrm{DO}_{2}\right)$ & $12.3 \%$ & $6.3 \%$ & $14.4 \%$ \\
\hline Stroke Volume Variation & $50.9 \%$ & $6.3 \%$ & $21.5 \%$ \\
\hline Near infrared spectroscopy & $14.2 \%$ & $4.6 \%$ & $5.1 \%$ \\
\hline Global end diastolic volume & $5.7 \%$ & $2.1 \%$ & $8.2 \%$ \\
\hline
\end{tabular}

KSA: Korean Society of Anesthesiologists, ASA: American Society of Anesthesiology respondents, ESA: European Society of Anaesthesiology respondents. We obtained permission by the publisher to use data from ASA and ESA. 
for not monitoring $\mathrm{CO}$ in high-risk surgery patients were a preference for measuring dynamic parameters rather than the direct measurement of $\mathrm{CO}(37 \%)$ and the invasiveness of current CO monitoring techniques (32\%). Moreover, $19 \%$ of the respondents felt that $\mathrm{CO}$ monitoring did not provide additional clinically relevant information (Table 2). However, $94 \%$ of the respondents indicated that oxygen delivery to tissues was of major importance during high-risk surgery.

\section{Volume management}

More than $80 \%$ of the respondents replied that BP (85\%) and UO (81\%) were diagnostic indicators of volume expansion, followed by CVP (73\%), clinical experience (71\%), and CO (57\%). Dynamic parameters were regarded as better indicators than TEE and PCWP (51\%) (Table 3). The respondents used primarily classic parameters such as increased BP and UO, decreased HR, and clinical experience to assess the hemodynamic effect of volume expansion. Half of the respondents routinely measured $\mathrm{CO}$ to assess the effects of volume expansion, and SVV was used more frequently than PPV or SPV among the dynamic parameters (Table 4). More respondents felt that SVV (20\%) or CO (17\%) was a better predictor of volume expansion than BP (9\%) or CVP (3\%) (Table 5).

The dynamic parameters of fluid responsiveness were measured by eyeballing (44\%), automatic measurement using specific software (41\%), and manual calculations (16\%).

The most commonly used fluid for volume expansion was hydroxyethyl starch (73\%), followed by crystalloid (18\%) and blood products (7\%).

Finally, $88 \%$ of the respondents believed that their current hemodynamic management approach could be improved.

Table 2. If You Do Not Monitor Cardiac Output Routinely in These Patients, What Are the Main Reasons for not Monitoring It? (Please, Mark All That Apply)

\begin{tabular}{|c|c|c|c|}
\hline \multirow{2}{*}{ Answer options } & $\begin{array}{l}\text { KSA respondents } \\
\qquad(\mathrm{n}=81)\end{array}$ & $\begin{array}{l}\text { ASA respondents } \\
\qquad(\mathrm{n}=157)\end{array}$ & $\begin{array}{l}\text { ESA respondents } \\
\quad(\mathrm{n}=142)\end{array}$ \\
\hline & Response percent & Response percent & Response percent \\
\hline $\begin{array}{l}\text { I use dynamic parameters of fluid responsiveness (Pulse Pressure } \\
\text { Variations, Systolic Pressure Variations, Plethysmographic Waveform } \\
\text { Variations) as surrogates for cardiac output monitoring }\end{array}$ & $37.0 \%$ & $54.1 \%$ & $60.6 \%$ \\
\hline Available cardiac output monitoring solutions are too invasive & $32.1 \%$ & $48.4 \%$ & $26.8 \%$ \\
\hline $\begin{array}{l}\text { Cardiac output monitoring does not provide any additional clinically } \\
\text { relevant information in this setting }\end{array}$ & $18.5 \%$ & $24.2 \%$ & $14.1 \%$ \\
\hline I use $\mathrm{SvO}_{2}$ and/or $\mathrm{ScVO}_{2}$ as surrogates for cardiac output monitoring & $7.4 \%$ & $13.4 \%$ & $26.1 \%$ \\
\hline Available cardiac output monitoring solutions are unreliable & $4.9 \%$ & $8.3 \%$ & $15.5 \%$ \\
\hline
\end{tabular}

KSA: Korean Society of Anesthesiologists, ASA: American Society of Anesthesiology respondents, ESA: European Society of Anaesthesiology respondents. We obtained permission by the publisher to use data from ASA and ESA.

Table 3. What Are Your Indicators for Volume Expansion in This Setting (Diagnostic Tools)? (Please, Mark All That Apply)

\begin{tabular}{lccc}
\hline \multirow{2}{*}{\multicolumn{1}{c}{ Answer options }} & KSA respondents $(\mathrm{n}=73)$ & ASA respondents $(\mathrm{n}=209)$ & ESA respondents $(\mathrm{n}=165)$ \\
\cline { 2 - 3 } & Response percent & Response percent & Response percent \\
\hline Blood pressure & $84.9 \%$ & $88.5 \%$ & $77.6 \%$ \\
Urine output & $80.8 \%$ & $83.3 \%$ & $77.0 \%$ \\
Clinical experience & $71.2 \%$ & $77.5 \%$ & $64.8 \%$ \\
Central venous pressure & $72.6 \%$ & $70.8 \%$ & $64.2 \%$ \\
Cardiac output & $57.5 \%$ & $49.3 \%$ & $53.3 \%$ \\
Pulse Pressure Variation or Systolic Pressure Variation & $50.7 \%$ & $45.0 \%$ & $55.8 \%$ \\
Transesophageal echocardiography & $34.2 \%$ & $43.5 \%$ & $28.5 \%$ \\
Pulmonary capillary wedge pressure & $27.4 \%$ & $38.8 \%$ & $24.2 \%$ \\
Plethysmographic Waveform Variation & $15.1 \%$ & $25.4 \%$ & $25.5 \%$ \\
Stroke Volume Variation & $50.7 \%$ & $19.1 \%$ & $36.4 \%$ \\
Mixed venous saturation $\left(\mathrm{SvO}_{2}\right)$ & $13.7 \%$ & $18.7 \%$ & $21.8 \%$ \\
Global end diastolic volume & $5.5 \%$ & $10.5 \%$ & $17.0 \%$ \\
Central venous saturation $\left(\mathrm{ScvO}_{2}\right)$ & $15.1 \%$ & $10.0 \%$ & $34.5 \%$ \\
\hline
\end{tabular}

KSA: Korean Society of Anesthesiologists, ASA: American Society of Anesthesiology respondents, ESA: European Society of Anaesthesiology respondents. We obtained permission by the publisher to use data from ASA and ESA. 
Table 4. How Do You Routinely Assess the Hemodynamic Effects of Volume Expansion in This Setting?

\begin{tabular}{|c|c|c|c|}
\hline \multirow{2}{*}{ Answer options } & $\begin{array}{l}\text { KSA respondents } \\
\quad(\mathrm{n}=72)\end{array}$ & $\begin{array}{l}\text { ASA respondents } \\
\quad(\mathrm{n}=203)\end{array}$ & $\begin{array}{l}\text { ESA respondents } \\
\quad(\mathrm{n}=162)\end{array}$ \\
\hline & Response percent & Response percent & Response percent \\
\hline Increase in blood pressure & $70.8 \%$ & $92.1 \%$ & $75.3 \%$ \\
\hline Increase in urine output & $75.0 \%$ & $84.7 \%$ & $73.5 \%$ \\
\hline Decrease in heart rate & $68.1 \%$ & $74.4 \%$ & $75.3 \%$ \\
\hline Increase in cardiac output & $51.4 \%$ & $59.1 \%$ & $54.3 \%$ \\
\hline Decrease in pulse pressure variation or systolic pressure variation & $43.1 \%$ & $56.7 \%$ & $54.9 \%$ \\
\hline Decrease in plethysmographic waveform variation & $22.2 \%$ & $28.6 \%$ & $25.9 \%$ \\
\hline Increase in mixed venous saturation $\left(\mathrm{SvO}_{2}\right)$ & $11.1 \%$ & $22.2 \%$ & $18.5 \%$ \\
\hline Decrease in stroke volume variation & $56.9 \%$ & $21.7 \%$ & $35.2 \%$ \\
\hline Increase in central venous saturation $\left(\mathrm{ScvO}_{2}\right)$ & $13.9 \%$ & $19.2 \%$ & $27.8 \%$ \\
\hline
\end{tabular}

KSA: Korean Society of Anesthesiologists, ASA: American Society of Anesthesiology respondents, ESA: European Society of Anaesthesiology respondents. We obtained permission by the publisher to use data from ASA and ESA.

Table 5. In Your Opinion, What Best Predicts an Increase in Cardiac Output Following Volume Expansion?

\begin{tabular}{lccc}
\hline \multirow{2}{*}{ Answer options } & KSA respondents $(\mathrm{n}=71)$ & ASA respondents $(\mathrm{n}=190)$ & ESA respondents $(\mathrm{n}=158)$ \\
\cline { 2 - 4 } & Response percent & Response percent & Response percent \\
\hline Transesophageal echocardiography & $12.7 \%$ & $26.8 \%$ & $17.7 \%$ \\
Cardiac output & $16.9 \%$ & $21.1 \%$ & $20.9 \%$ \\
Blood pressure & $8.5 \%$ & $14.2 \%$ & $5.7 \%$ \\
Pulse pressure variation or systolic pressure variation & $12.7 \%$ & $12.1 \%$ & $12.0 \%$ \\
Mixed venous saturation $\left(\mathrm{SvO}_{2}\right)$ & $5.6 \%$ & $7.9 \%$ & $5.7 \%$ \\
Stroke volume variation & $19.7 \%$ & $5.8 \%$ & $21.5 \%$ \\
Clinical experience & $11.3 \%$ & $5.3 \%$ & $3.2 \%$ \\
Pulmonary capillary wedge pressure & $5.6 \%$ & $2.1 \%$ & $3.2 \%$ \\
Central venous saturation $\left(\mathrm{ScvO}_{2}\right)$ & $0 \%$ & $2.1 \%$ & $1.9 \%$ \\
Central venous pressure & $2.8 \%$ & $1.1 \%$ & $3.2 \%$ \\
Global end diastolic volume & $0 \%$ & $1.1 \%$ & $3.8 \%$ \\
Plethysmographic waveform variations & $4.2 \%$ & $0.5 \%$ & $1.3 \%$
\end{tabular}

KSA: Korean Society of Anesthesiologists, ASA: American Society of Anesthesiology respondents, ESA: European Society of Anesthesiology respondents. We obtained permission by the publisher to use data from ASA and ESA.

\section{Discussion}

The results of our survey indicate that significant numbers of KSA respondents routinely monitor $\mathrm{CO}$ in high-risk surgery patients. However, CO was consistently optimized by $<20 \%$ of anesthesiologists, demonstrating a gap between the monitoring and optimization of $\mathrm{CO}$ in high-risk surgery patients. Furthermore, the respondents considered BP, CVP, HR, UO, and clinical experience to be better indicators or surrogates of volume expansion than CO or dynamic parameters of fluid responsiveness. The present results indicate that $\mathrm{CO}$ optimization is not widely used by Korean anesthesiologists, despite substantial evidence showing that $\mathrm{CO}$ optimization improves postoperative outcomes in high-risk surgery patients $[11,12]$.

The present survey was conducted to assess current hemodynamic monitoring practices, particularly CO monitoring and optimization, in high-risk surgery patients in South Korea. Besides IAP, CVP, and non-invasive BP, we found that more than half of the KSA respondents routinely monitored CO (59\%) and SVV (51\%). The monitoring frequencies of CO and SVV in our survey were higher than those reported in a survey by the ASA and ESA, in which routine CO monitoring was done by $35 \%$ of ASA and ESA respondents, and SVV was routinely monitored by $6 \%$ of ASA and $22 \%$ of ESA respondents [16]. This unexpectedly high frequency of CO and SVV monitoring may be attributable to the high rate $(79 \%)$ of Flotrac/Vigileo monitor use. We speculate that the minimal invasiveness of the system, which uses an existing arterial catheter and simultaneously monitors SVV, may have contributed to the high frequency of $\mathrm{CO}$ monitoring in high-risk surgery patients.

Our results show that more respondents optimized BP than $\mathrm{CO}$ or dynamic parameters. Despite the relatively high frequency of monitoring $\mathrm{CO}$, few respondents in the present study reported optimizing $\mathrm{CO}$ for $>50 \%$ of the intraoperative time, revealing a discrepancy between $\mathrm{CO}$ monitoring and optimization. This discrepancy is consistent with the survey findings of the ASA 
and ESA [16]. While evidence indicates that CO optimization or maximization improves the outcome of high-risk surgery patients in terms of postoperative complications, mortality, and hospital stay [18-20], our survey demonstrated that many anesthesiologists in Korea do not use a routine CO optimization strategy in their clinical practice. This is an opportunity for improvement. As stated by Dr. Michael Pinsky, "No monitoring tool, no matter how accurate, by itself has improved patient outcome" [21], suggesting that only the actual practice of $\mathrm{CO}$ optimization has the potential to improve outcome. Several explanations for this gap are as follows. First, the benefits of $\mathrm{CO}$ optimization are not universally accepted; some believe that CO maximization is unnecessary or may be harmful $[22,23]$. Second, because the benefits of hemodynamic optimization appear post-surgery (e.g., reductions in morbidity or the length of hospitalization), anesthesiologists, particularly those not involved in postoperative care, may not be aware of or concerned about patient outcomes during the intraoperative period [24]. Third, flow-based, protocol-oriented fluid management is labor-intensive and requires the frequent assessment of fluid responsiveness after each administration. The procedure is difficult to perform routinely in the busy operating room environment. Finally, the absence of guidelines or a protocol may contribute to an anesthesiologist's reluctance to adopt this approach. The development of a protocol and quality assurance process to improve postoperative outcomes may be helpful in resolving these uncertainties [25].

Identifying responders and non-responders to fluid administration is important to guide fluid therapy in high-risk surgery patients. Dynamic indices are now well accepted to be better predictors of fluid responsiveness than static indices in patients with mechanical ventilation [26]. The respondents in the current survey also recognized dynamic indices such as SVV as the best predictors of fluid responsiveness; only $3 \%$ believed that CVP is an accurate predictor. This observation is of major significance for at least two reasons. First, while Korean anesthesiologists understand that CVP is a weak predictor of fluid responsiveness, 93\% still monitor this variable during high-risk surgery, which is at least $20 \%$ higher than what had been reported by ASA and ESA members. Second, Korean anesthesiologists merely monitor CVP rather than try to optimize it, which raises the question of why CVP is still monitored in this setting. Recent quality improvement programs implementing $\mathrm{CO}$ optimization during major surgery have shown that this approach decreases the use of central venous catheters, which may, in turn, decrease the incidence of central line-related complications [9]. The results of our study indicate that many anesthesiologists in Korea still rely heavily on CVP in fluid management despite their recognition that dynamic parameters are better predictors of fluid responsiveness. Familiarity with traditional variables and a lack of implementation of formal protocols for $\mathrm{CO}$ optimization may be the reason for this result. This needs to be re-evaluated if the unusually high use of CVP monitoring has any advantage for hemodynamic monitoring during high-risk surgery in Korea.

\section{Study limitations}

The low response rate (4\%) to our survey, causing a high likelihood of non-responder bias, was largely due to the limitations of our survey method. We believe that the inclusion of a large number of incorrect e-mail addresses was the primary reason for the low response rate. Thus, it was difficult to estimate the denominator population, making it almost impossible to correctly estimate the response rate. This is a common weakness of e-mail- and web-based surveys [27]. Moreover, the majority of respondents practiced at university or general hospitals where many high-risk surgeries are performed, suggesting that the survey was not of interest to all KSA members. A topic that was of interest to only one faction of the target population is likely to have contributed to the low response rate [28]. As a result of these limitations, our survey respondents are not representative of the entire KSA membership; thus, careful consideration is needed when generalizing our findings.

In conclusion, the present study shows that despite a relatively high frequency of CO monitoring, many Korean anesthesiologists do not frequently optimize it in high-risk surgery patients.

\section{Acknowledgments}

The authors thank the KSA for advertising our survey and sending e-mails to its members. We particularly thank the anesthesiologists who participated in this survey.

\section{References}

1. Marik PE, Baram M, Vahid B. Does central venous pressure predict fluid responsiveness? A systematic review of the literature and the tale of seven mares. Chest 2008; 134: 172-8.

2. Osman D, Ridel C, Ray P, Monnet X, Anguel N, Richard C, et al. Cardiac filling pressures are not appropriate to predict hemodynamic response to 
volume challenge. Crit Care Med 2007; 35: 64-8.

3. Corcoran T, Rhodes JE, Clarke S, Myles PS, Ho KM. Perioperative fluid management strategies in major surgery: a stratified meta-analysis. Anesth Analg 2012; 114: 640-51.

4. Shoemaker WC, Appel PL, Kram HB, Waxman K, Lee TS. Prospective trial of supranormal values of survivors as therapeutic goals in high-risk surgical patients. Chest 1988; 94: 1176-86.

5. Gan TJ, Soppitt A, Maroof M, el-Moalem H, Robertson KM, Moretti E, et al. Goal-directed intraoperative fluid administration reduces length of hospital stay after major surgery. Anesthesiology 2002; 97: 820-6.

6. Kern JW, Shoemaker WC. Meta-analysis of hemodynamic optimization in high-risk patients. Crit Care Med 2002; 30: 1686-92.

7. Wakeling HG, McFall MR, Jenkins CS, Woods WG, Miles WF, Barclay GR, et al. Intraoperative oesophageal Doppler guided fluid management shortens postoperative hospital stay after major bowel surgery. Br J Anaesth 2005; 95: 634-42.

8. Zimmermann M, Feibicke T, Keyl C, Prasser C, Moritz S, Graf BM, et al. Accuracy of stroke volume variation compared with pleth variability index to predict fluid responsiveness in mechanically ventilated patients undergoing major surgery. Eur J Anaesthesiol 2010; 27: 555-61.

9. Kuper M, Gold SJ, Callow C, Quraishi T, King S, Mulreany A, et al. Intraoperative fluid management guided by oesophageal Doppler monitoring. BMJ 2011; 342: d3016.

10. Hood JA, Wilson RJ. Pleth variability index to predict fluid responsiveness in colorectal surgery. Anesth Analg 2011; 113: 1058-63.

11. Gurgel ST, do Nascimento P Jr. Maintaining tissue perfusion in high-risk surgical patients: a systematic review of randomized clinical trials. Anesth Analg 2011; 112: 1384-91.

12. Hamilton MA, Cecconi M, Rhodes A. A systematic review and meta-analysis on the use of preemptive hemodynamic intervention to improve postoperative outcomes in moderate and high-risk surgical patients. Anesth Analg 2011; 112: 1392-402.

13. Cannesson M, Desebbe O, Rosamel P, Delannoy B, Robin J, Bastien O, et al. Pleth variability index to monitor the respiratory variations in the pulse oximeter plethysmographic waveform amplitude and predict fluid responsiveness in the operating theatre. Br J Anaesth 2008; 101: 200-6.

14. Hofer CK, Senn A, Weibel L, Zollinger A. Assessment of stroke volume variation for prediction of fluid responsiveness using the modified FloTrac and PiCCOplus system. Crit Care 2008; 12: R82.

15. Lopes MR, Oliveira MA, Pereira VO, Lemos IP, Auler JO Jr, Michard F. Goal-directed fluid management based on pulse pressure variation monitoring during high-risk surgery: a pilot randomized controlled trial. Crit Care 2007; 11: R100.

16. Cannesson M, Pestel G, Ricks C, Hoeft A, Perel A. Hemodynamic monitoring and management in patients undergoing high risk surgery: a survey among North American and European anesthesiologists. Crit Care 2011; 15: R197.

17. Pearse RM, Harrison DA, James P, Watson D, Hinds C, Rhodes A, et al. Identification and characterisation of the high-risk surgical population in the United Kingdom. Crit Care 2006; 10: R81.

18. Donati A, Loggi S, Preiser JC, Orsetti G, Munch C, Gabbanelli V, et al. Goal-directed intraoperative therapy reduces morbidity and length of hospital stay in high-risk surgical patients. Chest 2007; 132: 1817-24.

19. Lobo SM, Lobo FR, Polachini CA, Patini DS, Yamamoto AE, de Oliveira NE, et al. Prospective, randomized trial comparing fluids and dobutamine optimization of oxygen delivery in high-risk surgical patients [ISRCTN42445141]. Crit Care 2006; 10: R72.

20. Pearse R, Dawson D, Fawcett J, Rhodes A, Grounds RM, Bennett ED. Early goal-directed therapy after major surgery reduces complications and duration of hospital stay. A randomised, controlled trial [ISRCTN38797445]. Crit Care 2005; 9: R687-93.

21. Pinsky MR. Hemodynamic monitoring over the past 10 years. Crit Care 2006; $10: 117$.

22. Gattinoni L, Brazzi L, Pelosi P, Latini R, Tognoni G, Pesenti A, et al. A trial of goal-oriented hemodynamic therapy in critically ill patients. SvO2 Collaborative Group. N Engl J Med 1995; 333: 1025-32.

23. Hayes MA, Timmins AC, Yau EH, Palazzo M, Hinds CJ, Watson D. Elevation of systemic oxygen delivery in the treatment of critically ill patients. N Engl J Med 1994; 330: 1717-22.

24. Miller TE, Roche AM, Gan TJ. Poor adoption of hemodynamic optimization during major surgery: are we practicing substandard care? Anesth Analg 2011; 112: 1274-6.

25. Michard F, Cannesson M, Vallet B. Perioperative hemodynamic therapy: quality improvement programs should help to resolve our uncertainty. Crit Care 2011; 15: 445.

26. Marik PE, Cavallazzi R, Vasu T, Hirani A. Dynamic changes in arterial waveform derived variables and fluid responsiveness in mechanically ventilated patients: a systematic review of the literature. Crit Care Med 2009; 37: 2642-7.

27. Draugalis JR, Coons SJ, Plaza CM. Best practices for survey research reports: a synopsis for authors and reviewers. Am J Pharm Educ $2008 ; 72: 11$.

28. Edwards P, Roberts I, Clarke M, DiGuiseppi C, Pratap S, Wentz R, et al. Increasing response rates to postal questionnaires: systematic review. BMJ 2002; 324: 1183 . 


\section{Appendix}

\section{Korean Society of Anesthesiology Hemodynamic Monitoring Questionnaire}

\section{Hemodynamic management in patients undergoing high-risk surgery}

For the following questionnaire, we will define high risk surgery patients as patients aged 18 years or older presenting for major surgery expected to last more than 1.5 hours and having at least two of the following criteria:

1. Cardiac or respiratory illness resulting in functional limitation

2. Extensive surgery planned for carcinoma involving bowel anastomosis

3. Predictable acute massive blood loss (>2.5 liters)

4. Aged over 70 years with functional limitation of one or more organ systems

5. Septicemia (positive blood cultures or septic focus)

6. Respiratory failure $\left(\mathrm{PaO}_{2}<60 \mathrm{mmHg}\right.$ on $\mathrm{FiO}_{2}>0.4$ i.e. $\mathrm{PaO}_{2}: \mathrm{FiO}_{2}$ ratio $<150 \mathrm{mmHg}$ or ventilation $>48$ hours $)$

7. Acute abdominal catastrophe (e.g. pancreatitis, perforated viscous, gastro-intestinal bleed)

8. Acute renal failure (urea $>20 \mathrm{mmol} / \mathrm{L}$, creatinine $>260 \mu \mathrm{mol} / \mathrm{L}$ )

9. Surgery for abdominal aortic aneurysm

10. Disseminated malignancy

1. If you do not provide or directly supervise anesthesia for this type of patient, please indicate so by filling in the box below. Thank you

$\square$ I do not provide or directly supervise anesthesia for this type of patient.

$\checkmark$ I provide or directly supervise anesthesia for this type of patient.

2. How many times in a typical work week do you provide or directly supervise anesthesia for a high risk surgery patient?

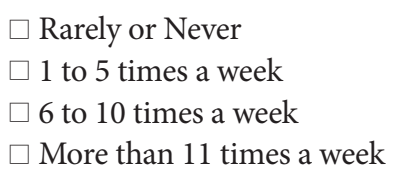

3. Which statement best describes your practice setting?

$\square$ University Hospital
$\square$ General Hospital
$\square$ Private Practice
$\square$ Other
Other (please specify)

4. Does your institution or group have a written protocol, care guide, or statement concerning hemodynamic management in this setting?
$\square$ Yes
$\square$ No
$\square$ Unsure or don’t know

5. What hemodynamic monitoring do you routinely use for the management of high risk surgery patients? (please, mark all that apply)

Plethysmographic Waveform Variation

$\square$ Global end diastolic volume

$\square$ Central venous pressure

$\square$ Stroke Volume Variation

$\square$ Mixed venous saturation $\left(\mathrm{SvO}_{2}\right)$

$\square$ Invasive arterial pressure

$\square$ Central venous saturation $\left(\mathrm{ScvO}_{2}\right)$

$\square$ Oxygen delivery $\left(\mathrm{DO}_{2}\right)$

$\square$ Pulse Pressure Variation

$\square$ Near infrared spectroscopy 
$\square$ Pulmonary capillary wedge pressure

$\square$ Transesophageal echocardiography

$\square$ Non-invasive arterial pressure

$\square$ Systolic Pressure Variation

$\square$ Cardiac output

6. How frequently do you try to optimize arterial pressure intraoperatively in this setting?

$\square$ Never

$\square$ Less than 5 percent of the time

$\square$ Between 6 and 25 percent of the time

$\square$ Between 26 and 50 percent of the time

$\square$ Between 51 and 75 percent of the time

$\square$ More than 75 percent of the time

\section{How frequently do you try to optimize central venous pressure in this setting?}

$\square$ Never

$\square$ Less than 5 percent of the time

$\square$ Between 6 and 25 percent of the time

Between 26 and 50 percent of the time

Between 51 and 75 percent of the time

$\square$ More than 75 percent of the time

\section{How frequently do you try to optimize cardiac output in this setting?}
$\square$ Never
$\square$ Less than 5 percent of the time
$\square$ Between 6 and 25 percent of the time
$\square$ Between 26 and 50 percent of the time
$\square$ Between 51 and 75 percent of the time
$\square$ More than 75 percent of the time

\section{How frequently do you try to optimize central venous oxygen saturation $\left(\mathrm{ScvO}_{2}\right)$ in this setting?}

$\square$ Never

$\square$ Less than 5 percent of the time

$\square$ Between 6 and 25 percent of the time

$\square$ Between 26 and 50 percent of the time

$\square$ Between 51 and 75 percent of the time

$\square$ More than 75 percent of the time

\section{How frequently do you try to optimize mixed venous oxygen saturation $\left(\mathrm{SvO}_{2}\right)$ in this setting?}

$\square$ Never

$\square$ Less than 5 percent of the time

$\square$ Between 6 and 25 percent of the time

$\square$ Between 26 and 50 percent of the time

$\square$ Between 51 and 75 percent of the time

$\square$ More than 75 percent of the time

11. How frequently do you try to optimize dynamic parameters of fluid responsiveness (Pulse Pressure Variations, Systolic Pressure Variations, Plethysmographic Waveform Variations) in this setting?

\footnotetext{
$\square$ Never

$\square$ Less than 5 percent of the time

$\square$ Between 6 and 25 percent of the time

$\square$ Between 26 and 50 percent of the time

$\square$ Between 51 and 75 percent of the time

$\square$ More than 75 percent of the time
} 
12. If you optimize hemodynamics in your high risk surgery patients, when do you do it?

$\square$ Before anesthesia induction

$\square$ After anesthesia induction

$\square$ During surgery

$\square$ In the postoperative period

\section{When do you think that hemodynamic optimization is of most value?}

$\square$ Before anesthesia induction

$\square$ After anesthesia induction

$\square$ During surgery

$\square$ In the postoperative period

14. Regarding respiratory variations in arterial pulse and/or systolic pressure: how do you measure these indices in the clinical setting?

$\square$ Eyeballing

$\square$ Manual calculation

$\square$ Automatic measurement using specific software

If you use automatic measurement using a dedicated software, please specify which one

\section{What technique do you use to monitor cardiac output? (please, mark all that apply)}

$\square$ LiDCO Monitor

$\square$ Thoracic bioimpedance

$\square$ Esophageal Doppler

$\square$ Vigileo Monitor

$\square$ Swan Ganz catheter

$\checkmark$ PiCCO Monitor

Transesophageal echocardiography

$\square$ Other

Other (please specify)

16. If you do not monitor cardiac output routinely in these patients, what are the main reasons for not monitoring it? (please, mark all that apply)

$\square$ I use $\mathrm{SvO}_{2}$ and/or $\mathrm{ScvO}_{2}$ as surrogates for cardiac output monitoring

$\square$ Cardiac output monitoring does not provide any additional clinically relevant information in this setting

$\square$ I use dynamic parameters of fluid responsiveness (Pulse Pressure Variations, Systolic Pressure Variations, Plethysmographic Waveform Variations) as surrogates for cardiac output monitoring

$\square$ Available cardiac output monitoring solutions are too invasive

$\square$ Available cardiac output monitoring solutions are unreliable

Reminder:

In this questionnaire we define high risk surgery patients as patients aged 18 years or older presenting for major surgery expected to last more than one and a half hours and presenting at least two of the following criteria:

1. Severe cardiac or respiratory illness resulting in severe functional limitation

2. Extensive surgery planned for carcinoma involving bowel anastomosis

3. Predictable acute massive blood loss ( $>2.5$ liters)

4. Aged over 70 years with functional limitation of one or more organ systems

5. Septicaemia (positive blood cultures or septic focus)

6. Respiratory failure $\left(\mathrm{PaO}_{2}<60 \mathrm{mmHg}\right.$ on $\mathrm{FiO}_{2}>0.4$ i.e. $\mathrm{PaO}_{2}: \mathrm{FiO}_{2}$ ratio $<150 \mathrm{mmHg}$ or ventilation $>48$ hours $)$

7. Acute abdominal catastrophe (e.g. pancreatitis, perforated viscous, gastro-intestinal bleed)

8. Acute renal failure (urea $>20 \mathrm{mmol} / \mathrm{L}$, creatinine $>260 \mu \mathrm{mol} / \mathrm{L}$ )

9. Surgery for abdominal aortic aneurysm

10. Disseminated malignancy 
17. What are your indicators for volume expansion in this setting (diagnostic tools)? (please, mark all that apply)

$\square$ Central venous pressure

$\square$ Central venous saturation $\left(\mathrm{ScvO}_{2}\right)$

$\square$ Urine output

$\square$ Cardiac ouput

$\square$ Transesophageal echocardiography

$\square$ Mixed venous saturation $\left(\mathrm{SvO}_{2}\right)$

$\square$ Pulse Pressure Variation or Systolic Pressure Variation

$\square$ Stroke Volume Variation

$\square$ Pulmonary capillary wedge pressure

$\square$ Plethysmographic Waveform Variation

$\square$ Global end diastolic volume

$\square$ Clinical experience

$\square$ Bloodpressure

18. How do you routinely assess the hemodynamic effects of volume expansion in this setting?

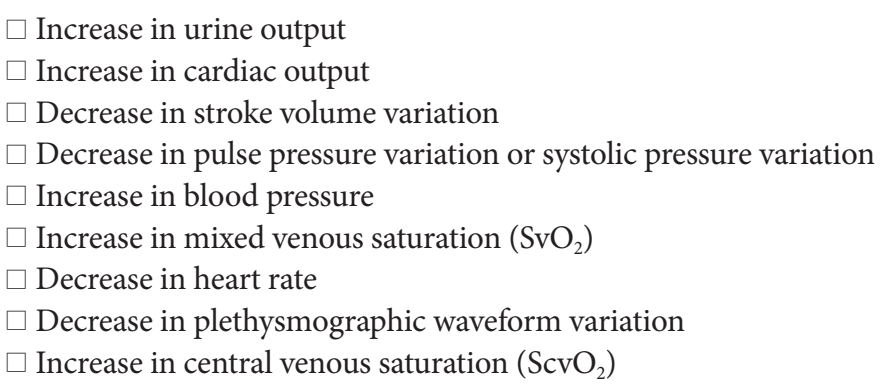

19. In your opinion, what best predicts an increase in cardiac output following volume expansion?

$\square$ Central venous pressure

Mixed venous saturation $\left(\mathrm{SvO}_{2}\right)$

$\square$ Global end diastolic volume

$\square$ Stroke volume variation

$\square$ Transesophageal echocardiography

$\square$ Pulse pressure variation or systolic pressure variation

$\square$ Central venous saturation $\left(\mathrm{ScvO}_{2}\right)$

$\square$ Plethysmographic waveform variations

$\square$ Cardiac output

$\square$ Clinical experience

$\square$ Pulmonary capillary wedge pressure

$\square$ Blood pressure

\section{What is your first choice solution for volume expansion?}

Human albumin

$\square$ Hydroxyethyl starch solutions

$\square$ Crystalloids

$\square$ Dextrans

$\square$ Blood derived products

$\square$ Gelatin

\section{Do you or your department/group manage these patients in the intensive care unit?}

$\square$ Yes

$\square$ No 
22. If not, who manages these patients in the ICU?

$\square$ Critical Care physicians

$\square$ Surgeons

$\square$ Other anesthesiologists

$\square$ Other physicians than anesthesiologists or surgeons

$\square$ Mixed population

23. Do you believe that oxygen delivery to the tissues is of major importance in patients during high risk surgery?

$\square$ Yes

$\square$ No

24. What parameter(s) is (are) involved in oxygen delivery to the tissues?

$\square$ Arterial Pressure

$\square$ Cardiac Output

$\square$ Central venous pressure

$\square \mathrm{PaO}_{2}$

$\square \mathrm{SaO}_{2}$

$\square$ Hemoglobin

25. Do you believe that your current hemodynamic management could be improved?

$\square$ Yes

$\square$ No

\section{Which statement best describes you?}

$\square$ I am an anesthesiologist predominantly caring for transplant surgery patients

$\square \mathrm{I}$ am an anesthesiologist predominantly caring for cardiac surgery patients

$\square$ I am an anesthesiologist predominantly caring for patients not having transplant or cardiac surgery

$\square$ I am an anesthesiologist predominantly practicing intensive care

$\square$ I am an anesthesiologist caring for a variety of patients

$\square$ Other

Other (please specify)

\section{Did your training include a fellowship year?}

$\square$ Yes
$\square$ No
$\square$ Not applicable

28. If yes, which one(s)?

$\square$ Critical care medicine

$\square$ Pediatric anesthesiology

$\square$ Pain

$\square$ Research

$\square$ Cardiac anesthesiology

$\square$ Other

Other (please specify)

29. When did you finish your training?

$\square$ After the year 2000

$\square$ 1990-1999

$\square$ 1980-1989

$\square$ Prior to 1980 
30. How many intensive care unit beds does your primary hospital have?
$\square 7$ or less
$\square 8$ to 10
$\square 11$ to 15
$\square 16$ to 20
$\square 21$ to 30
$\square 31$ to 40
$\square$ More than 40

31. How many beds does your primary hospital have?
$\square 100$ or less
$\square 101$ to 250
$\square 251$ to 500
$\square 501$ to 1,000
$\square$ More than 1,000

32. What is the population of your practice location?
$\square$ Less than 10,000
$\square 10,000$ to 50,000
$\square 50,001$ to 100,000
$\square 100,001$ to 500,000
$\square$ More than 500,000

33. In which city (province) is your practice?

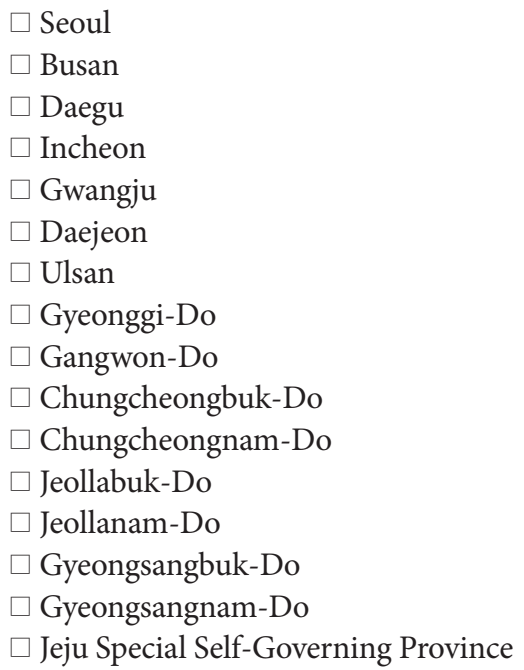

Thank you very much for taking time to answer these questions. 